\title{
MUSEOLOGIENS PLASS I VITENSKAPENES SYSTEM
}

\author{
Friedrich Waidacher
}

"Hvis noen for tretti, ja bare tjue år siden hadde snakket eller skrevet om 'museologi' som en egen vitenskap, ville han av mange bli møtt av en medlidende eller nedsettende latter. Nå er det ganske visst annerledes.»

Slik skrev direktøren for Grüne Gewölbe i Dresden, Johann Georg Theodor Gresse, $i$ 1883 - altså for 112 àr siden - $i$ 'Zeitschrift für Museologie und Antiquitätenkunde sowie verwandte Wissenschaften', som han grunnla i 1877. ${ }^{1}$

Tidsskriftet 'Museumskunde' begynte å komme ut i 1908 og eksisterer som kjent fortsatt. Her skrev Karl Koeschau i 1924, altså for mer enn to generasjoner siden, om museumskunnskap som en selvstendig disiplin «som har sikret seg et rom, om enn beskjedent, i vårt humanistiske arbeids store byggverk, og gjort det beboelig." ${ }^{2}$

To ting kan vi merke oss hos begge forfatterne. For det forste en optimisme som fikk sin sørgelige korrigering $i$ en hard virkelighet. For det andre finnes hos de begge begrepene 'museologi' og 'museumskunnskap', og de har ennå i dag en plass $i$ vitenskapelig spräkbruk. Hva betyr de egentlig?

Jeg vil si det kort: det siste betyr nettopp som termen sier, kunnskap om en bestemt institusjon, museet. Museumskunnskap er altså ingen vitenskap, men er en beskrivelse av en særskilt institusjonstypes, altså museets, oppkomst og utviklingsbetingelser, former og arbeidsmåter. En institusjon som for omkring to århundrer siden utviklet seg til et særskilt medium for kommunikasjon. Hverken mer eller mindre.

Det førstnevnte derimot, museologien, inkluderer riktignok det underordnede begrepet museumskunnskap, men det omfatter likevel mye mer enn dette, griper dypere og lenger. Museologien oppfyller kravene til en vitenskap. Jeg skal i det følgende forsøke å vise hvorfor og hvordan.

Dagens museologi er en forholdsvis ung disiplin sammenlignet med sosiologi, psykologi eller økologi, likevel eldre enn kybernetikk og informatikk. Dens røtter strekker seg imidlertid langt tilbake:

Det hittil tidligste kjente forsøket på en teori om museer daterer seg til Tyskland i 
136 renessansens begynnelse. I 1565 utkom det $\mathrm{i}$ München et arbeide av den belgiske legen Samuel von Quiccheberg med en utførlig beskrivelse av en samling naturalia og artefakter, framstilt som en ideell utdanningsinnretning. ${ }^{3}$

Med dette betydelige arbeide utformet Quiccheberg allerede et grunnmotiv for innsamlingspraksis og en museumsteori som fikk innflytelse og ble videreutviklet fram til slutten av 1700 -tallet.

At det faktisk ikke dreier seg om et enkelt tilfelle vil en, om enn flyktig, eksemplifisering av forfatternavn fra de følgende århundrer vise. De representerer den museologiske tenkningens tidlige historie, og skal lede over til den nåtida som jeg har større anledning til å sysselsette meg mer inngående med.

Navnene kommer fra ulike land i Europa. De gir oss anledning til å tenke over hvor viktig refleksjonen over den irrasjonelle oppførselen hos mennesket alltid har vært. Den førte til etableringen av kunst- og kuriositetskabinetter, portrettgallerier, glyptotek og endelig til offentlige statlige universalmuseer, for bare å nevne noen kategorier. ${ }^{4}$ Jeg velger ut

- fra 1600-tallet; Ole Worm, lege og medisinprofessor i København, Jan Amos Comenius, den store pedagogen, og medisineren og botanikeren Johann Daniel Major i Kiel;

- fra 1700-tallet; professoren og bibliotekaren Daniel Wilhelm Moller, arkitekten og matematikeren Leonhard Christoph Sturm, kjøpmannen og humanisten Caspar Friedrich Jenckel, som skrev seg for Neckelius;

- fra 1800-tallet; geniet Goethe, den franske juristen og kunstkjenneren Louis Viardot, den russiske bibliotekaren og filosofen Nikolai Fjodorowitsch Fjodorow.
Før og etter første verdenskrig ble det utviklet storartede framtidsrettede tankesystem framfor alt i Tyskland, Østerrike og USA - Alfred Lichtwark, John Cotton Dana, Hans Tietze, Arthur W. Melton og Otto Neurath må nevnes. Utviklingen ble imidlertid avbrutt med de dogmatiske, menneskeforaktende tenkesett, som kom under den barbariske perioden da så mange livstråder brutalt ble kuttet av, og ytterst få kunne redde seg over den Engelske kanal eller Atlanteren.

Den moderne museologiens teoretiske utgangspunkt tilhører derfor tida etter andre verdenskrig. De grunnleggende spørsmålene kunne drives videre på et bredt grunnlag etter etableringen av ICOM i 1946.

På slutten av 1950-tallet fulgte så, delvis uavhengig av museene selv, de første beskjedne overenskomster om museologiens definisjon som vitenskap.

Endelig framla Zbynék Stránsky i 1963 sin kunnskapsteoretisk baserte definisjon og skisse til en systematisk museologi. ${ }^{5}$

Etter lang tids tvil i den utenomeuropeiske museumsverdenen, forårsaket dels av den dominerende anglosaksiske grunninnstillingen som var pragmatisk, dels gjennom de språkbarrierer som vanskeliggjør tilegnelsen av sentral- og østeuropeisk litteratur, ble man også her kjent med dette filosofisk baserte teoretiske utgangspunkt:

Ordet museologi er mer enn 100 år gammelt, mens en teoretisk diskusjon om museene strekker seg helt tilbake til 1600-tallet og utgjør en del av det moderne museets framvekst. Museologiens teoretiske grunnlag har altså eksistert gjennom fire århundrer uten at museumsfolk har vært seg det bevisst. ${ }^{6}$

I 1971 ble museologi anerkjent som ut- 
danningsfag av ICOM's generalkonferanse. Ved generalkonferansen seks år senere ble den internasjonale museologikomitéen (ICOFOM) etablert og godkjent.

Samtidig, altså i 1977, ble det i samarbeid mellom ICOM's internasjonale dokumentasjonskomité (CIDOC) og det ungarske sentralinstituttet for landets museer i Budapest dannet en terminologisk arbeidsgruppe som i 1986 utga Dictionarium Museologicum, ei sammenlignende museologisk ordbok på 20 språk.

Ved utgangen av 1980-tallet fantes det omkring et halvt tusen kurs og program på høyskolenivå for utdanning av museumspersonale, der de fleste er knyttet til emner eller teknikker som tradisjonelt forekommer i museer.

Over 100 kurs betegnes derimot uttrykkelig som museologiske og tilbyr også en allmenn teoretisk museologi. Omkring to tredjedeler av alle kurs og programmer finnes i USA ${ }^{7}$; den teoretiske grunnforskningen foregår derimot i Europa.

\section{HVA ER DA MUSEOLOGI IFØLGE VITENSKAPENS NAVAERENDE POSISJON?}

Grunnleggende sett er museologi et overordnet begrep som inkluderer beskriving, klassifisering og definisjon av det normgivende teoretiske grunnlaget, foruten metoder, teknikker og hjelpemidler knyttet til fenomenets praksis. Til dette kan føyes en kort definisjon:

Museologien tilbyr en teoretisk forklaring og praktisk tillempning av en spesiell relasjon mellom mennesket og den omgivende virkeligheten.

Denne utskillende og verdsettende måten å forholde seg på er museologiens kunnskapsobjekt. At dette til sist ble utarbeidet, definert og gitt en særskilt terminologi kan vi takke Zbynék Stránsky for. Han har gjort det med hjelp av en filosofisk analyse, på tross av en overveldende motstand fra en pragmatisk majoritet innen museumsverdenens etablissement. Han har fătt støtte bare fra et fătall tenkere - jeg nevner her bare den polske museologen Wojciech Gluzinski.

De egentlige museene og deres forgjengere tjente under tidligere epoker ganske forskjellige formål. De hadde og har ennå forskjellige organisasjonsformer, formål, innhold og arbeidsmåter. Men deres mening var hele tida den samme.

Museet som konkret institusjon i vår tid er følgelig bare én dynamisk fungerende form blant mange mulige. Denne formen har oppstått under bestemte historiske og samfunnsmessige vilkår og hadde helt annerledes forgjengere. Den kommer også uunngåelig å bli forandret i framtida. Av denne grunn kan ikke museet selv - som det $\mathrm{i}$ lang tid feilaktig har vært antatt være museologiens forskningsobjekt. Museet er nemlig i seg selv ikke noe mål, men et uttrykk for en idé, noe menneskelig.

Museologiens studieobjekt er altså det holdningsmønster som får mennesket til ofte med stort slit og store oppofringer - å velge ut og bevare bestemte gjenstander fra den fysiske verdens mangfold som vitnesbyrd om bestemte saksforhold. Og disse gjenstander framstår intersubjektivt som så viktige at de ikke skal bevares bare for samtida, men også formidles til ettertida. Dette spesielle forholdet kaller vi etter Stransky for musealitet.

Hvilken plass kan vi nå gi museologien i vitenskapenes system?

Det ville være lettsindig å snakke om ett 
FRIEDRICH WAIDACHER

138 enhetlig og logisk sammenhengende system. Noe slikt finnes som bekjent ikke. Vitenskap er summen av det som gjennom forskning, undervisning og litteratur er blitt til den samlede viten. Vitenskap som en metodisk drevet intersubjektiv prøvbar forskning i teori og praksis, er en prosess som aldri er statisk. Den skaper nye disipliner gjennom å åpne nye områder av viten og gjennom å overføre tillemping av metoder mellom ulike områder. Utfra et valgt synspunkt finnes derfor ulike systemer som alle har gyldighet.

Jeg skal forsøksvis innordne museologien i noen av dem: Museologi er

- etter sitt formål praktisk og tillempet (i stedet for rent teoretisk);

- etter sitt innhold en idealistisk vitenskap, ettersom den dreier seg om tidløse gjenstander;

- etter sin erkjennelsesbasis så vel aposteriorisk-empirisk som apriorisk-rationalistisk;

- etter sin orientering det som vi med Dilthey gjennom hundre år har kalt en humanistisk vitenskap. Her finner museologien med sikkerhet seg best til rette

Til forskjell fra naturvitenskapene, som strever etter å lage allmenngyldige utsagn om hendelses- og virkningssammenheng i naturen, og med kausale forklaringer som metode, anstrenger humaniora og kulturvitenskapene seg for å bygge innsikt om enkeltstående og historiske fenomener, betydningsinnhold og sammenheng, og dette gjennom hermeneutiske metoder som forstående empati, deltakende observasjon, tolking og omskriving. Mens naturvitenskapenes objekt er den levende og døde naturen, sysselsetter humaniora og kulturvitenskaper seg med uttrykksformer, objektiveringer av den menneskelige bevissthet, dvs. alle former for kultur som mennesket produserer i egenskap av skapende og åndelig vesen. ${ }^{8}$
- etter sin form (i motsetning til en lovmessig vitenskap) en kulturvitenskap som beskriver det særskilte og derved benytter en generaliserende metodikk;

- etter sin form for sannsynlighetsbevis en fenomenologisk begrunnelse (i stedet for transcendental bevisførsel);

- til slutt en vitenskap med lavt abstraksjonsnivå (sammenlignet med den sterkt abstraherende matematikken) og høy grad av konkretisering (sammenlignet med logikken).

Fra dette forsøket på å karakterisere museologiens plass er det lett å innse at det ikke rører seg om en monolittisk, men tvertimot om høyt integrert vitenskap. Den behandler jo også i sitt omfattende saksinnhold en tidløs eksistensform som vi synes å kunne se allerede i de tidligste spor fra menneskelig virksomhet.

Som basis i alle museale framstillinger, alle konkrete utrykk for musealitet, finnes en åndelig, immateriell dimensjon, som er sammenlignbar med grunnleggende menneskelige behov som trygghet, verdsetting og selvrealisering. Egentlig dreier det seg om menneskets lengten etter å overskride seg selv og grensene gitt av tid og sted.

Mens museologien studerer en polyvalent stillingstaken hos mennesket og dets materielle uttrykk, har den behov for utveksling og samarbeid med en mengde andre vitenskaper. Nettopp fordi den potensielt har som formål å studere og søke å forklare alle tenkbare konkrete fenomen i den naturlige og menneskeformede virkeligheten sub specie musealitatis, kan den bare eksistere som tverr- og flervitenskapelig.

For det første trenger museologien i den daglige praksis interdisiplinær støtte av alle fagvitenskaper som tjener det primære 
gjenstandstudiet - fra geologien til kunsthistorien. Videre trenger den de særskilt utviklede vitenskaper som - i likhet med museologien selv - søker å generalisere former og lovmessigheter for grunnleggende fenomener, som f.eks. filosofi, psykologi og kommunikasjonsvitenskap. Alle disse - som dreier seg om kildematerialenes vitenskaper, nabovitenskaper og museologien selv - fungerer sammen med begrepet musealitet som utgangspunkt. En vitenskap blir materiale for en annen. De er, som Karl Jaspers har uttrykt det, "hverandres hjelpevitenskaper".

Hvor enn museologien har sin plass, er en ting sikkert: den kan på ingen måte plasseres som 'bindestrek-vitenskap' mellom fagvitenskapene. Tvertimot: museologien kan i likhet med filosofien «bare som en selvstendig disiplin og med et eget 'science community' utvikle sine særskilte funksjoner."'

Som enhver ung vitenskap har museologien selvsagt ikke bare venner, den blir også avvist, ignorert, ja motarbeidet. Hva er årsaken til dette?

I den siste tida, etter Thomas S. Kuhn, ${ }^{10}$ vet vi hvordan det går med en vitenskap som stiller spørsmål ved til nå alminnelige tenkemåter og prøver ut nye retninger:

I likhet med hver ny vitenskap har museologien introdusert et nytt paradigme, dvs. et allment akseptert vitenskapelig standpunkt som gjennom ei viss tid og innen en viss krets av fagfolk tilbyr normgivende problemformuleringer og deres losning.

Nye teorier utløser, når de framføres, regelmessig samme avvisende reaksjon fra en del av de fagmenn som får sitt forskningsområde berørt.

For dem betyr den nye teorien en endring av de regler som inntil da har dominert det vitenskapelige arbeidet. Det har nødvendigvis følger for omfattende, allerede vellykket avsluttede vitenskapelige arbeider. Derfor er en ny teori, selv om dens anvendingsområde kan virke begrenset, ikke bare en byggestein som kan legges som et tillegg til den allerede pågående forskningens resultat. $\AA$ akseptere den krever som oftest at en tidligere teori omarbeides og at tidligere fakta revurderes, en dyptgående revolusjonær prosess, som sjelden kan gjennomføres av en enkeltstående forsker og aldri fullføres fra en dag til en annen."

Følgelig er hver ny teori provoserende og møtes uunngåelig med fortrengning, mistenksomhet og åpent fiendskap. Eksemplene fra historien er mange - jeg påminner bare om navnene Galilei, Newton, Lavoisier og Helmholtz.

Nettopp fordi en ny teori bryter med en etablert vitenskapelig tradisjon og skaper en ny praksis, som følger andre regler og har en annen begrepsverden, kan den åpenbart framtre når en kjenner at den gamle tradisjonen har ført helt feil avsted. Denne innsikten tjener som innledning til en undersøkelse av den krisesituasjon som rår og ulykkeligvis hører de problemer som den leder til heller til psykologens enn til historikerens fag ... Hvordan opptrer vitenskapsmenn når de blir klar over at noe er blitt helt feil ... og det på et stadium ... som deres utdanning på ingen måte har forberedt dem for? ${ }^{12}$

Med denne formuleringen «... som deres utdanning ikke har forberedt dem for» har også et av museumspraksisens grunnproblemer blitt innringet.

En formell museologisk utdanning finnes - som jeg har vist ovenfor - bare for den siste generasjon. Ettersom det minst vil vare et tiår innen velutdannede mennesker kan bli virksomme på et yrkesområde, er ennå lenge en majoritet $\mathrm{av}$ 
140 museumsmedarbeiderne 'dilettanter' når det gjelder museologisk skolering. De er riktignok som regel utmerkede fagfolk og håndverkere, de er velutdannede $\mathrm{i}$ sine respektive gjenstandsvitenskaper eller praktiske spesialiteter, men egentlig ikke for sin faktiske yrkesutøvelse.

Fra dette følger at museologien - i likhet med andre nye vitenskaper - mange steder møtes med mistro: særskilt der utilstrekkelige og fra lang tid tilbake foreldede innstillinger har hatt tid til å etablere seg, blir museologien avvist med avsky, ettersom følgene av gamle teoriers falsifisering skulle føre til radikale forandringer av metoder, målsettinger og dermed den praktiske livssituasjon.

Derfor er det forståelig at også erfarne museumsfolk viser seg å stille seg tvilende overfor begrepet museologi. Det representerer en trussel ettersom det krever en ny tenkemåte, ettersom det stiller spørsmåltegn ved gamle vaner. Dertil er museologien i stand til å sette punktum for dyrkingen av private vitenskapelige kjepphester, som gjennom generasjoner har foregått på det offentliges bekostning i mange store museer. Også praktisk museumsarbeid blir det nemlig mulig å bedømme. Museologien tilbyr til og med en anvendbar målestokk for arbeidets kvalitet.

Bortsett fra de pinlige vurderinger som en museologisk analyse kan føre til, er museologien i stand til på alle nivåer å høyne museumsvirksomhetens samfunnsmessige relevans. Basert på mange års teoretisk forskning drevet på et empirisk grunnlag, rår museologien over metoder som muliggjør et resultat fra konkret museumsarbeid som ikke kunne oppnås med ureflektert empiri eller metoder hentet fra andre fagvitenskaper. Endelig muliggjør museologien også vurderinger av arbeidsmåter som har vært ansett som umulig å bedømme på et målbart vis innen en fagvitenskapelig tenkemåte, ettersom de ble antatt å tilhøre den emosjonelle-kunstnerlige-intuitive sfæren og derfor uvilkårlig unndrog seg rasjonell bedømming.

Jeg skal helt kort anføre noen eksempler fra praksis i det daglige museumsarbeidet:

\section{EKSEMPEL I \\ Vesensforskjellen mellom museer og andre institusjoner som formidler 'det minne- verdige'}

Det handler her først og fremst om sammenligning med institusjonstyper som bibliotek, arkiv, skoler, forskningsinstitutt og databanker. De egenskapene som skiller disse ligger i hva som er de primære mediene, metodene og målsettingene. Museets primære medium er det konkrete og unike - naturobjekt og artefakter (menneskelagde gjenstander). Den primære formidlingsmetoden er utstillingen ikke undervisning eller utlån. Det primære målet er den forståelsesbaserte opplevelsen og ikke viten eller ferdigheter.

Når den egne viktige egenarten hos en institusjon blir forlatt, oftest som følge av ukyndighet eller feilbedømminger, oppstår misforståelser som gir vanskelige konsekvenser. De fører ofte til resultatsløse anstrengelser ettersom en med inadekvate midler forsøker å oppfylle andre institusjoners oppgaver. Samtidig blir de egne forpliktelser og mål, som heller ikke på en kompetent måte kan oppfylles av andre, nedprioritert.

Et typisk eksempel på dette i museene er at den spesifikt museale presentasjonen av 
musealier fortrenges til fordel for fagvitenskapelige publikasjoner, som egentlig er en forskningsinstitusjons medium, eller forsøkene på å drive undervisning i museet, noe som er skolenes primære oppgave.

\section{EKSEMPEL II \\ Prinsippene for utvalg av museumsobjekter}

På samme måte som språkets natur er selektiv for å fungere i en kommunikasjon, må museenes innsamlingsvirksomhet anvende utvalgsmetoder som museologien stiller til rådighet. Bare på en slik måte kan et museum bevare og videreføre et samlingsinnhold som er intersubjektivt akseptabelt.

Av denne grunn må museologene stilt overfor virkelighetens gjenstandsmasse treffe et valg. Dels for å kunne tegne et rettferdig bilde av verden omkring seg, dels for overhodet å kunne beholde og videreføre sitt utvalg til etterverden.

$\AA$ gjøre et utvalg for en museumssamling er en skapende prosess, der museologen treffer sitt valg innenfor rammene av et definert og intersubjektivt holdbart verdisystem. Derved velges ikke objektene bare som autentiske elementer fra sin virkelighet, men også som belegg for og bærere av samfunnsmessige verdier. De blir derfor i sin museale kontekst ikke ikoner eller 'Dinge an sich', men nøkler til kunnskap og forståelse, som 'ting for oss' (Maurice Merleau-Ponty).

Derved må det vektlegges at den museale verdien i form av kultur-, kunnskapsog forestillingsverdier gjennom sin betydning på en grunnleggende måte skiller seg fra alle andre verdier. Disse kan være individuelle eller gruppebestemte, $i$ alle fall er de utenommuseale - det gjelder handelsverdi, investeringsverdi eller samlerverdi.
Musealitet strever mot objektivitet og må i det minste være intersubjektivt gyldig. Derfor kan bare det museologiske utgangspunktet i sin helhet utskille, forstå og bedømme de spesielle egenskapene i den omgivende virkeligheten, og endelig utforske framstillingsformer og betydningsendringer.

Hvorvidt de valgte objektene som er utpekt som mulige bærere av musealitet, faktisk sammenfaller med de museale krav til representativitet og bevis for en bestemt samfunnsmessig virkelighet, kan bare en vitenskapelig basert museologisk prøving endelig ta stilling til.

Kunnskap og bedømmelse er likevel ikke samme sak. Av det følger at både gnoseologiens og aksiologiens arbeidsredskaper må anvendes for museologien. ${ }^{13}$

Derfor er den aktive seleksjonen av utslagsgivende betydning. Museale samlingsobjekter velges nemlig ofte på en uvitenskapelig måte på basis av fagvitenskapenes kriterier, eller på grunn av tilfeldige synspunkter, f.eks. tilbud, tilfeldigheter, personlige sympatier og andre faktorer.

Men dette betyr at en ukritisk og passiv musealisering fører til et ikke representativt utvalg og dermed til feiltolkning av en kulturhelhet. Samtidig unndrar kulturens talsmenn seg den tradisjonelle kulturelle bearbeidingsoppgaven, 'tenkningens sosialarbeid', og fjerner derved grunnlaget for ideen om en kulturarv. "Det som er overlevert kan ikke betraktes som noe ervervet eller arvet». ${ }^{14}$

I motsetning til dette kan det gjennom den bevisste samtidstilknyttede virkelighetsanalysen i hvert tilfelle utformes et fra museologisk synspunkt levende kulturarvbegrep, - en kulturarv som ikke bygges opp ved en kritikkløs og passiv overtakelse 
142 av fortidas levninger. Gjennom et aktivt utvalg og gjennom den betydningsendring som er knyttet til en gjenstands profesjonelle musealisering, skapes en ny kulturell virkelighet. Gjennom dette kan samfunnets bevissthet påvirkes, og det vil til slutt oppnås en tilbakevirkning på tilstanden $\mathrm{i}$ den omgivende virkeligheten.

\section{EKSEMPEL III}

\section{Museumskommunikasjonens egenart}

Museumskommunikasjon oppnås gjennom visning, presentasjon av musealier og deres tolkning. Alle museale kommunikasjonsformer, også når gjenstandene ikke vises, men kommuniseres i form av publikasjoner eller programmer, utgår fra musealiene selv og må derfor danne et sammenhengende system. Dertil er den museale kommunikasjonen på grunn av sin egenart, de autentiske gjenstandene, umulig å erstatte med noe annet. ${ }^{15}$

Museumsutstillingen er et budskap. Den formidler noe abstrakt ved hjelp av det konkrete. Dens spesielle betydning ligger i at den ikke bare formidler kunnskap, men også ved at den gjennom musealiene beviser kunnskapens gyldighet. De er ikke på noen måte en imitasjon av virkeligheten, men en egen kulturell virkelighet. Gjennom det skiller den seg både gjennom sitt vesen og i sin synlighet på en grunnleggende måte fra all annen presentasjon. Framvisningen alene av gjenstander er en eksponering, en oppvisning, mens museumsutstillingen viser fram og forteller. Den presenterer og gjør nærværende.

Museumsbesøkernes subjektive opplevelse er en personlig oppdagelse av innhold, som de - umiddelbart eller senere opplever som betydningsfullt, forstår og verdsetter. Potensielt kan de da sette gjenstandene inn i den sammenheng i virkeligheten, som de museologisk med hjelp av en gnoseologisk og aksiologisk prosess ble valgt ut fra.

Ideelt foreligger det en sjanse for at besøkeren innordner seg $\mathrm{i}$ en metapersonlig forståelsesstruktur som vedkommende person ikke bare får personlig utbytte av, men gjør at det fra et kulturskapende synspunkt, virker for kvaliteten i sitt samfunn. ${ }^{16}$

Innsikten om at objektene representerer et komplekst nærvær som er underlagt et mangfold av tolkninger, har viktige konsekvenser for hvordan museene oppfatter og presenterer seg selv. De fleste museene er ennå ordnet etter den strenge taksonomien og klassifikasjonen fra slutten på 1800-tallet, der en forestilte seg at objektene burde være utstilt konsekvent, enhetlig og linært. Under tiden har imidlertid forestillingene med tro på et eneste, helt dominerende teoretisk system gitt plass for en mer bevisst forståelse for betrakterens rolle i tolkningen. ${ }^{17}$

Museumsutstillingen er en ypperlig symbolsk uttrykksmåte, ettersom de presenterte objektene, også da de kan se høyst attraktive ut, ikke eksisterer for seg selv, men som henvisninger til bestemte virkeligheter, som de skal muliggjøre tolkningen av.

En forutsetning for denne tolkningen er den håndgripelige kontakten - eller i det minste øyekontakten - med de museale tingene. Følgelig er museet først og fremst ikke en plass for viten, men for forståelse. Gjennom møtet med autentiske ting tilbyr museet som medium en enestående mulighet til å gjøre den fysiologiske betraktningen til et instrument for en total og forstående opplevelse. 


\section{EKSEMPEL IV \\ Museumspedagogikk som tilbud om selvfor- stäelse}

Det pedagogiske arbeid i museene skiller seg på en avgjørende måte fra andre utdanningsformer, i og med det bygger på den museale kontekstens spesielle forutsetninger og vilkår, og retter seg mot aldeles spesielle mål. Dens viktigste kjennetegn er at den i første omgang ikke strekker seg mot å utdanne et publikum, men mot å muliggjøre tilgjengeligheten av et kunnskapsinnhold.

Kommunikasjon i museer kan hverken rette seg mot eller oppnå innlæring i begrenset pedagogisk forstand, ${ }^{18}$ ettersom museenes innhold og mottakerne oppretter en forbindelse gjennom helt andre kanaler.

Problemene med pedagogisk orienterte begrep i museer har også gjennom lang tid vist at de hviler på et inadekvat grunnlag. De bygger på den feilaktige antakelse at erfaringer og forskningstradisjoner som gjelder for allmenne utdanningsinstitusjoner skulle være anvendbare på museer. Dette er imidlertid umulig ettersom museene generelt sett framstår med egenskaper som ikke gjør dem sammenlignbare med skoler eller utdanningsinstitusjoner for voksne. ${ }^{19}$

Kommunikasjon på informasjonsnivå har forst og fremst kunnskapskarakter. Kommunikasjon på musealienes niva har forst og fremst ontologisk karakter. ${ }^{20}$

I den museale kommunikasjonen handler det om å skape forutsetninger for å gjøre en opplysningsressurs tilgjengelig. Det uformelle møtet tilbys med det unike og eksemplariske som en indre opplevelse kan utløses gjennom. I motsetning til dette står det opplysningsarbeid som tjener tilegnelsen av en materiell kunnskap og den formelle utdannelsen som fører til funksjonsforståelse. Begge tilhører den praktiske og teoretiske innlæringen.

Derfor er øynenes møte med de autentiske objektene eller musealiene den egentlige og unike formen for museal kommunikasjon. Et slikt møte har mange plan - det omfatter emosjonelle, sanselige og intellektuelle kategorier. Det kan utvilsomt også gi opphav til læring - men da alltid gjennom en individuell respons og frivillig.

Pedagogisk arbeid i museene skiller seg på denne måten vesentlig fra tradisjonell skoleundervisning. Det er frivillig, uformelt, ikke nivåbundet, kjenner ingen læreplaner og prøver. Museumsbesøkeren kan komme og gå etter behag, de kan se en utstilling $\mathrm{i}$ eget tempo og utfra egne interesser. Til hovedmålene for den museale læringen hører å stimulere besøkerne til å utvikle sine sanser. ${ }^{21}$

Frankfurterskolens kritiske teori har lært oss at vitenskapsmannens moralske plikt overfor samfunnet er å «utover forståelsesog begrunnelses-sammenhengen for sin kunnskap også å utvikle tanker om dens anvendelse. Den enkelte forsker og forskningssamfunnene kan ikke nøye seg med å produsere viten, de må også reflektere over konsekvensene for samfunnet av sin virksomhet og de nye kunnskapene. ${ }^{22}$

På denne måten må det spørsmålet forstås som Zbynék Stránsky nylig stilte om museets mening. Som følge av den globale krisen har det allerede eksistensiell betydning. ${ }^{23}$ Mer enn noensinne er det nemlig nødvendig at museumsfolk prioriterer sine samlingers og utstillingers kulturskapende rolle, uavhengig av museologiens plass blant vitenskapene. 
144 Det ville være ønskelig at det ikke går så lang tid som det vanligvis gjør innen museologien får en slik anerkjennelse i museumsverdenen at de oppnådde innsiktene kan stilles til samfunnets rådighet, nå og i framtida.

Foredrag ved konferansen "30 airs undervisning $i$ museologi ved Masaryk Universitet Brno", 12-13. april 1995, Masaryk Universitet Brno, Tjekkia. Oversatt fra tysk av Per-Uno Agren og John Aage Gjestrum

\section{NOTER}

1. Graesse, J. T. G.1883. «Museologie als Fachwissenschaft", Zeitschrift fir Museologie und Antiquitätenkunde 6: 13

2. Koetschau, K. 1924. "Ein Wort zum Abschied», Museumskunde 17: 207

3. Kfr. Berliner, R.1928. «Zur älteren Geschichte der allgemeinen Museumslehre in Deutschland», Münchner Jahrbuch der bildenden Kunst, N. F. V: 327-352 (Nyopptrykt i R. Land, (Hrsg.) 1988.

Beiträge aus der deutschen museologie und Museumsgeschichtsschreibung I. (1875 bis 1931). Institut für Museumswesen. Schriftenreihe, 26. Berlin.)

4. Kfr. om det følgende sammenfatningen $\mathrm{i}$ Waidacher, F. 1993. Handbuch der Allgemeinen Museologie. Wien; Köln; Weimar: 125-145.

5. Kfr. Stránskv, Z. Z. 1965. Predmet muzeologie. Brno.

6. Teather, L. 1985. «Preparation for museum carreers", i: M. Segger (Comp.), Museums operation manual. Victoria: 27.

7. Glaser, I. R., M. M. Anderson og R. Fogg. 1988. Museums Studies International, 1988. Washington, D. C.

8. Salamun, K. 1992. Was ist Philosophie? Tübingen: 84 .

9. Etter Baumgartner, H. und O. Höffe, «Zur Funktion der Philosophie in Wissenschaft und Gesellschaft», i: Salamun, op. cit.: 303-304.

10. Kuhn, T.S. 1976. Die Struktur wissenschaftlicher
Revolutionen. Frankfurt a. M.

11. Kuhn, op. cit.: 21.

12. Kuhn, op. cit.: 99.

13. Kfr. Stránsky, Z. Z. 1971. «Der Begriff der Museologien, i: Einfuihrung in die Museologie. Museologické sesity, Supplementum, 1.

14. Jeudy, H. P. 1987. Die Welt als Museum. Berlin: 8.

15. Stránsky, Z. Z. 1974. Brno: Education in museology. Brno.

16. Waidacher, F. 1990. «Rays of hope». Museum News, 46: 3-4.

17. Smith, C. S. 1989. "Museums, artefacts, and meanings", i: P. Vergo (Hrsg.) The new museology. London: 19.

18. Weschenfelder, K. og W. Zacharias. 1981. Handbuch Museumspädagogik. Düsseldorf.

19. Treinen, H. 1981: «Das Museum als Massenmedium - Besucherstrukturen, Besucherinteresse und Museumsgestaltung», i: CECA/ICOM (Hrsg.)., Museumsarchitektur fiur den Besucher. Hannover: 14.

20. Stránsky, Z. Z. 1990. Museologie - ihre Entstehung und Stellung im Kontext der Entwicklung der Wissenschaften. Vortrag bei der Tagung "Aspekte der Musealität» an der Universität Umeå, Schweden, vom 19. bis 22.4. 1990.

21. Booth, J. H., G. H. Krockover und P. R. Woods. 1982. Creative museum methods and educational techniques. Springfield, Ill.

22. Salamun, op. cit.: 166.

23. Stránsky, Z. Z. 1995. "Museen in der Krise der Menschheit». Ikke offentliggjort manuskript.

Friedrich Waicacher har vart direktor for det prestisjefylte museumskomplekset Joanneum i Graz, Østerrike. Han var i mange år medlem $i$ komiteen for den europeiske museumsprisen og har utgitt den omfattende 'Handbuch der allgemeinen Museologie', 1993. Adr. Mönchegg 34, A-8742 St Wolfgang-Kienberg, Österreich 